\title{
Perception and Conceptualization of Visual Arts in Ekphrastic Poetry
}

James Heffernan is the author of the most popular contemporary definition of ekphrasis: "ekphrasis is the verbal representation of visual representation" (Heffernan 1993: 3). This statement shifts the original tension in ekphrastic texts from the long-standing antagonism between the verbal and the visual to the fact that ekphrasis deals with visually represented objects: "what ekphrasis represents in words, therefore, must itself be representational" (ibid.: 3).

Claus Clüver proposes an extension of Heffernan's definition: "ekphrasis is the verbalization of real or fictitious texts composed in a non-verbal sign system" (Clüver 1998: 49). The definition relates to the semiotic concept of text, understood here as a complex sign in any sign system. Clüver calls verbalization "a form of verbal re-presentation that consists of more than a name or a title" (ibid.: 45). As such it retains certain degree of enargeia: vividnessor a particularly vivid description (enargeia in Greek; evidentia or perspicuitas in Latin). Clüver's clarification also integrates approaches towards the subject of ekphrasis which may be fictitious or real, visual and non-visual, an artwork or an everyday object. It broadens the scope of ekphrasis, attributing ekphrastic potential to various aspects of the interart dialogue. Clüver avoids drawing clear lines defining various forms of intersemiotic relationships, maintaining that it would create an obstacle for interarts studies, due to the fact that "[b]oundary lines tend to have the fixity that does not reflect the actual situation in contemporary interarts discourse" (ibid.: 47).

Ekphrastic texts transgress semiotic boundaries, combining the spatial medium of the visual arts with the temporal medium of literature. In the case of ekphrastic poetry, intersemiotic translation will be looking for equivalence between the two systems: the verbal and the visual modes of artistic expression. Due to the fact that each element has a certain place or function in a sign system, thus in translation it may be substituted 
by another element which has the same place or function in another system. Equivalent does not mean identical, so the studies in the field of ekphrasis should not limit themselves to the description of similarities or differences between the source text (visual) and target text (verbal). They need to show the mechanisms governing such a translation. Among others we may distinguish: a transition of particular details from the source to the target, an omission of some aspects of the visual artwork for the sake of other elements, a substitution of certain visual traits with verbal techniques which more precisely convey poetic thought. Thus, intersemiotic translation is an act of interpretation made clear, ekphrastic poems are traces of invisible and frequently unobservable processes. They are fascinating also for the readers because in most cases they are is able to have an immediate access to the object of poetic ekphrasis.

Cognitive poetics is particularly apt in this context as it offers an ample set of ready-made tools which can be used in a critical analysis. In cognitive view, the meaning of a poem or a picture is not to be found in the text alone, but in the conceptual content the text evokes in the reader's or the viewer's mind. Art perception is an activity making sense of a work of art the same way as making sense of the real word. An art viewer applies methods already known from the interaction with everyday world, so there is no specific cognitive model for aesthetic experiences. What distinguishes those two types of perception is the degree of cognitive effort involved in their production.

There are certain features shared by poetic translation and ekphrasis: it provides a kind of afterlife to the original, being a propagation of its cultural, aesthetic, and ideological aspects. Ekphrasis widens the impact of a work of art and its content, it is a process of decoding and encoding: a poem may explain certain painterly techniques, exemplify visual metaphors by means of poetic metaphors, iconically represent the theme of the visual artwork. As much as translation, ekphrasis is both an activity and a final result (Lhermitte 2005: 101-103).

The contemporary American poet Donald Hall ekphrastically represents one of the most popular pictures by Edvard Munch, entitled The Scream. The poem, published in its first version in 1957 consists of two parts. The first one attempts to describe and verbally recreate the overwhelming pictorial content of Munch's painting, while the other part refers to the process of perception of a visual artwork and creation of ekphrastic poetry. 
The Scream by Donald Hall ${ }^{1}$

Observe. Ridged, raised, tactile, the horror of the skinned head is there. It is skinned which had a covering-up before, and now is nude, and is determined

by what it perceives. The blood not Christ's, blood of death without resurrection, winds flatly in the air. Habit foists conventional surrender to one

response in vision, but it fails here, where the painstaking viewer is freed into the under-skin of his fear.

Existence is laid bare, and married

to a movement of caught perception where the unknown will become the known as one piece of the rolling mountain becomes another beneath the stone

which shifts now toward the happy valley which is not prepared, as it could not be, for the achieved catastrophe which produces no moral upshot, no curtain, epilogue, nor applause, no Dame to return purged to the Manse (the Manse is wrecked) - not even the pause, the repose of art that has distance.

We, unlike Munch, observe his The Scream making words, since perhaps we too know the head's "experience of extreme disorder". We have made our bravo, but such, of course, will never equal the painting. What is the relation? A word, which is at once richly full of attributes, thinginess, reason,

reference, time, noise, among others; bounces off the firm brightness of paint as if it had no substance, and errs toward verbalism, naturally. Mayn't 
we say that time cannot represent space in art? "The fascination of what's impossible" may be present, motivating the artist to move.

So the poet, the talker, aims his words at the object, and his words go faster and faster, and now he is like a cyclotron, breaking into

the structure of things by repeated speed and force in order to lay bare in words, naturally, unworded insides of things, the things that are there.

The first line of Hall's poem offers the reader a chance to look at the work of art as if through the poet's eyes. It starts with an imperative: "Observe, the horror/ of the skinned head is there". The reader's attention is directed by the poet, who enters the domain of perception through the sense of touch and focuses on tangible attributes of the picture: "[r]idged, raided, tactile". How can something we can see but not touch be be perceived as tactile? It is due to a basic metaphor: SEEING IS TOUCHING that our eyes are understood as hands and identify what they touch. When we feel something sharp or rough the movement of our fingers becomes cautious and hesitant, it slows down or interrupts. Correspondingly, when we look at a picture riddled with details, where the use of colours, brush strokes and the depicted scene evoke contemplative and ominous mood, our gaze cannot just sweep the painting (Lakoff and Turner 1989: 142). Instead, our sight fixes on the elements that are most powerful visually and contextually, as the process of perception is aesthetic, emotional and intellectual. One of the most notable ideas of Cognitive Linguistics is that our physical embodiment determines the nature of human experience. Human body serves as an important resource for the construal of reality and understanding of abstract concepts (Evans 66-68). Evoking the touch experience also means provoking the sensory and emotional aspect of human body. These sensimotor adjectives stress the feeling of closeness and immediacy of what the first noun in the poem represents: "the horror".

The strong visual impact of the painting is achieved through the contrast between the pale human figure, represented by a common metonymy PART FOR WHOLE as a "skinned" or "nude head" and the red sky which occupies most of the background. In the poem, the color of blood is mapped onto the color of the sky, such mapping of images 
leads us to map knowledge of one image onto the other, forming a so called one-shot metaphor. One-shot metaphors are "more fleeting metaphors which involve not the mappings of concepts but rather the mapping of images (Lakoff and Turner 1989: 89). Here the domains are mental images and images structure includes attribute structure - such things as color, intensity of light, physical shape, texture. "The blood not Christ's,/ blood of death without resurrection, winds flatly in the air". Even though the sky in nature can possibly have a red hue, we must resort to conceptual knowledge associated with the red colour and yet another metonymy: DEATH IS SHEDDING BLOOD. Why this metonymical expression? One reason is that it highlights the picture's menacing atmosphere, the visual image of blood winding in the air is more powerful that a verbal statement and it points directly to the content of Munch's painting. Moreover, this metonymy is frequently used in biblical language and it activates CHRISTANITY frame, highlights the concept of divine death and determines a certain perspective in which the frame is viewed. Here the frame is mentioned only to be negated "blood not Christ's" or "death without resurrection", so it introduces a human, more deterministic point of view.

The poet observes that a traditional critical analysis of a work of art will not be possible in this case. "Habit foists conventional surrender to one / response in vision, but it fails here". Hall juxtaposes in this poem two types responses to art. This short, emotionally intensive representation of Munch's painting is an example of an ekphrastic moment when the poet attempts to stop, 'to freeze' this very intimate and personal encounter with art. On the one hand it is possible to treat art a closed system which enables an intellectual analysis of its elements. In the case of painting it is the analysis of its style, technique or historical context. On the other hand there are such works of art whose charm, appeal or grandness result form their emotional content which frequently seems to be more important than the formal aspects.

Ekphrastic poetry commonly involves multiple seeing schema, inside and outside the painting (Fig. 1). The traditional components of the schema include (Langacker 1987: 73): 


\begin{tabular}{|c|c|c|c|}
\hline & inside & outside' $^{\prime}$ & outside" \\
\hline VIEWER & human figure & poet & $\begin{array}{l}\text { reader (implied } \\
\text { viewer) }\end{array}$ \\
\hline VISUAL FIELD & nature & painting & painting (limited) \\
\hline $\begin{array}{l}\text { OBJECT OF } \\
\text { PERCEPTION }\end{array}$ & catastrophe & painting & poet's perception \\
\hline PERSPECTIVE & close, immediate & close, immediate & more detached \\
\hline FOCUSING & $\begin{array}{l}\text { sky } \\
\text { valley }\end{array}$ & $\begin{array}{l}\text { head } \\
\text { sky } \\
\text { valley }\end{array}$ & $\begin{array}{l}\text { head } \\
\text { sky } \\
\text { valley } \\
\text { mountain } \\
\text { avalanche } \\
\text { theatre }\end{array}$ \\
\hline
\end{tabular}

Figure 1. Prototypical viewing arrangement in The Scream by Donald Hall

As we can see, the perception schema is tripartite, as it engages three distinct viewers: the human figure depicted in the painting, the poet/ speaker who gets inspiration from seeing The Scream by Munch and finally the reader who becomes an implied viewer of the ekphrastic translation of Munch's artwork. Interestingly, the last viewer's (the reader's) perception, 144 even though limited to what the poet conveys, focuses on much more elements than the other viewers'. The poet introduces extra objects and ideas to the painting, marked in italics in Figure1. In order to explain the visual content, the framework of DRAMATIC PERFORMANCE is used, with its integral elements of classical drama: curtain, epilogue, applause, resolution, catharsis. The visual medium is verbally interpreted by means of theatrical performance, which itself is an example of intermediality. The notion of intermediality is understood here as "a communicativesemiotic concept, based on the combination of at least two medial forms of articulation" (Rajewsky 2005: 52). The speaker of the poem stresses the temporal character of verbal arts, due to the fact that they do end at some point, whether they are read or performed. On the contrary, visual arts are always 'there' ('there' is deictically repeated twice in the poem), they are atemporal, so they do not create such a distance between themselves and the viewer: " - not even a pause, a repose of art that has distance". Munch's picture certainly does not distance itself from the viewer. On the contrary, its bright colors, bold brush strokes, and sinusoid lines completely overwhelm the viewer, as if attracting towards the inside of the painting. The scared, and scary, figure placed in the central point of the painting has become a universal symbol of the existential fear, and affects us psychologically. 
The other part of Hall's poem is devoted to the process of creation of ekphrastic poetry. Now the speaker uses the personal pronoun 'we' which refers to an average person who attempts to reconstruct verbally the meaning or formal organization of Munch's painting or to express their admiration of certain painterly techniques. The quote incorporated into the poem "experience of extreme disorder" sounds unnatural in this context, as if borrowed from an art catalogue or a critical review on Edvard Munch. Thus, the emotional impact and charismatic illusion of the artwork which are present in the first part of the poem are broken here, now understanding of the arts depends on our cultural capital, and the experience and expertise based on previous contacts with visual artworks.

Hall stresses in the poem this long-term love and hate relationship between the sister arts, the visual and the verbal: "We have made our bravo / but such, of course, will never equal the painting". The idea that poetry cannot equal painting brings us back to Leonardo Da Vinci who applies the term paragone, an Italian word meaning "comparison", which in the context of interarts relationship also implies "competition". Leonardo supports the higher value of painting among other disciplines, posing a question whether poetry or painting was better at representing the nature. He attempts to convince us that painting possesses a greater immediacy of the effect on the viewer, it is also more universal as it "needs no interpreters of various languages as letters do. [Painting] satisfies the human species immediately, not differently than things produced by nature do" (Leonardo, Richter 2008: 187).

The poem also alludes here to another poetic work, a poem by W. B. Yeats entitled The Fascination of What is Difficult. Even though for Yeats creation of poetry was inspirational and fascinating, it was temporarily perceived by him as drudgery under the heavy burden of running of the Abbey Theatre and formal constraints of bardic poetry. For Hall "The fascination with what is impossible" refers to the act of creation of ekphrastic poetry, the representation of the visual by means of the verbal, and spatiality through temporality. Hall's poem, published 1957, in some mysterious way anticipates and very practically exemplifies an important aspect of W. J. T. Mitchell's theory: three stages which constitute an ekphrastic act, published by Mitchell in Picture Theory in 1994. The first phase "ekphrastic indifference", derives from the idea that ekphrasis is unattainable: that there is a relationship between words and images, but language, no matter how much detailed and precise 'can never bring its visual presence before us in the way pictures do' (Mitchell 1995: 152). The second is "ekphrastic hope", developing out of the writers feeling that 
the visual can be captured in a verbal form and language can reconstruct an absent object, thus "the impossibility of ekphrasis is overcome in imagination or metaphor" (ibid.: 152). As a result, an "image text", a new, hybrid form is created. The third phase is "ekphrastic fear": "the moment of resistance or counter desire that occurs when we sense that the difference between verbal and visual might collapse and the figurative, imaginary desire of ekphrasis might be realized literally and actually" (ibid.: 154). A traditional expression of this fear may be encountered in Lessing's Laokoön where the poets are warned that "they should not regard the limitations of painting as beauties of their own art" (ibid.: 68-69). Each mode of artistic expression, as Lessing argues, should know its limitations and should not attempt to cross its own boundaries. Such a transference between visual and verbal art is perceived as promiscuous and idolatrous, in Mitchell's words, as "a magical technique that threatens to fixate the poet and the listener" (ibid.: 156). Contemporary poetry treats visual arts not as rivals but as points of departure for a discussion of the status of arts in postmodern times. The relationship between the visual and the verbal, especially the notion of tension may be explicated on the example of a funambulist. A tightrope walker requires a tensioned wire in order to maintain balance between two points. The tension keeps the funambulist 'in-between', were it removed, the laws of gravity would immediately bring the walker down. Similarly, ekphrastic poetry occupies a liminal, transient, intermedial space between two different modes of artistic expression. The representational and mimetic uncertainties together with the "ekphrastic fear" do not constitute an impediment to poetic creativity. Contrarily, they contribute to the creation of the literary form which eludes too easy classifications, yet still causes considerable stir among poets, literary critics and readers.

These three groups of people share their interest in poetry as a source of beautiful, sublime and exceptional expression of human thoughts and emotions. Poetry is commonly thought to achieve this special effect through the application of various stylistic devices, metaphor and metonymy among others. Traditional theories of metaphor, born with Aristotle, identify metaphors as pertaining to language and stylistics, functioning as literary devices employed for special rhetorical effects. Metaphorical meaning is understood to be fresh and novel and does not reflect the pre-existing conceptualizations of human mind. The notion of metaphor presented in this study is based on the definition originally formed by George Lakoff and Mark Johnson in Metaphors We Live By (1980), a work that has revolutionized metaphor theory. The contemporary theory of metaphor offered by the cognitive scholars also in subsequent 
publications, assigns a great role to metaphor as "pervasive in everyday life, not just in language but in thought and action" (Lakoff, Johnson 1980: 3). Verbal metaphors do not have only an ornamental function by means of which complex poetic ideas are put forward. Instead, verbal metaphors reflect both every day and literary conceptual mappings in which we conceptualize mostly abstract domains: time, ideas, emotions etc. Lakoff and Turner suggest that "metaphor is anything but peripheral to the life of the mind. It is central to our understanding of our selves, our culture, and the world at large" (Lakoff, Turner 1989: 214). However, in order to understand poetic metaphors one should understand first how metaphorical is our everyday speech. Poetry gives insight into the most essential aspects of human life and helps us comprehend them in terms of basic metaphorical expressions which may be transformed, extended or manipulated in the minds of the poets.

The last two stanzas of "The Scream" poem employ the conceptual metaphor POET IS A CYCLOTRON. This novel metaphor is an extension of PEOPLE ARE MACHINES metaphor which expresses human characteristics in terms of mechanical constructions. In conceptual metaphor theory, the image-schematic structure of the target domain constrains which image-schematic structures from the source domain are mapped onto it. Metaphorical mappings contain the following elements: slots in the source domain schema (a cyclotron) which are mapped onto the target domain (a poet); relations - the metaphor POET IS A CYCLOTRON is a mapping of the structure of cyclotron onto the domain of POET in such a way that it establishes appropriate correspondences between ELECTRIC PARTICLES PRODUCTION and POETIC CREATION, between ELECTRONS and WORDS etc.; properties in the source domain get mapped onto the target domain, e.g. a cyclotron emits particles with considerable speed and force, which maps onto the idea of the poet who uses his mental creative forces to produce a poem; knowledge of the source domain that allows us to draw interferences about the domain which are mapped onto interferences in the target domain. The source domain contains the characteristics of a cyclotron: its ability to accelerate and emit outwards charged particles, and to bombard other atoms, and its use of magnetic force. In the target domain, we have poetic creation as it is performed, the source of inspiration (the painting), the verbalization of thoughts and feeling, and a certain creative effort:

So the poet, the talker, aims his words at the object, and his words go faster and faster, and now he is like a cyclotron [...] 
As far as general metaphorical meanings are concerned, we need to be really cautious and observant. A cyclotron is not simply a metaphor for the mechanization of poetic production, or the amount of poetic effort or stamina involved in the creation of ekphrastic poetry, or for words which may become dangerous and kill, because a cyclotron emits radioactive material or for words which destroy the Other taking into account the fact that cyclotrons are used in cancer therapy. The poem exists on a more abstract level produced by the metaphor; it presumably may be "about" all these things through the image schemas that represent the various aspects of what it means to write an ekphrastic poem. Readers may agree or differ to some extent on the possible readings of the poem. However, all these readings must be conceptually justified. One of constraints observed by Turner is that mappings should make use of such conceptual metaphors which function also beyond the conceptualization proposed by the poem. Another constraint is the "reality check" the use of everyday knowledge which should be in accord with conventional metaphors (ibid.: 146). Thus the reading that the words of poetry may be lethal or destructive is not justifiable in the general context of The Scream.

Cognitive poetics makes it possible to show that different interpretations of poetry arise from the readers' selection of different topologies and mappings to make sense of the text according to their own knowledge, experience or mental predispositions. As Ruth Webb has noted about classical ekphrasis, the product of ekphrasis is and will always remain "present in the imagination and absent from the world perceived by the senses" (Webb 2009: 169). Being a mental entity, it naturally invites various conceptualizations and interpretations. Similarly to the way in which conceptual metaphor theory reconciles sometimes divergent views on the object of conceptualization, ekphrasis attempts to bridge the gap between visual and verbal arts. Contemporary poets who respond with extreme sensitivity to the "visual turn" in culture, frequently avoid description, a traditional and well-established mode of ekphrasis. This results from their awareness of the illusory status of "the verbal representation of visual representation". Though it is possible to find and analyze elements of intersemiotic transfer in ekphrastic poetry, we should be aware that ekphrasis is a conceptualization of the visual input, rather than one-to-one translation from visual to verbal arts. Therefore I believe that a cognitive poetics approach towards ekphrasis complemented with rigorous attention to textual details will offer an invaluable insight into ekphrastic poetry. 


\section{References}

Clüver, Claus (1998). "Quotation, Enargeia, and the Functions of Ekphrasis". In: Pictures into Words. Theoretical and Descriptive Approaches to Ekphrasis. Eds. Else Jongeneel and Valerie Robillard. (35-52). Amsterdam: VU University Press.

Evans, Vyvyan, and Melanie Green (2006). Cognitive Linguistics: An Introduction. London: Lawrence Erlbaum Associates.

Heffernan, James A. (1993). Museum of Words: The Poetics of Ekphrasis from Homer to Ashbery. Chicago: University of Chicago Press.

Hollander, John (ed.) (1995). The Gazer's Spirit: Poems Speaking to Silent Works of Art. Chicago: University of Chicago Press.

Lakoff, George, and Mark Johnson (1980). Metaphors We Live By. Chicago: University of Chicago Press.

Lakoff, George, and Mark Turner (1989). More than Cool Reason: A Field Guide to Poetic Metaphor. Chicago: University of Chicago Press.

Langacker, Ronald W. (1987). Foundations of Cognitive Grammar. Stanford: Stanford University Press.

Leonardo, Thereza Wells, and Irma A. Richter (2008). Leonardo Da Vinci: Notebooks. Oxford [u.a.]: Oxford University Press.

Lessing, Gotthold E. (2005). Laocoon: An Essay Upon the Limits of Painting and Poetry. Mineola, NY: Dover Publications.

Lhermitte, Corinne (2005). "A Jakobsonian Approach to Film Adaptations of Hugo's Les Misérables". Nebula 2 (1) (March): 93-107 [accessed: June 12, 2013].

Mitchell, W. J. Thomas (1995). Picture Theory: Essays on Verbal and Visual Representation. Chicago: University of Chicago Press.

Rajewsky, Irina (2005). "Intermediality, Intertextuality, and Remediation: A Literary Perspective on Intermediality". Intermediality: History and Theory of the Arts, Literature and Technologies (May): 43-64 [accessed: Aug 11., 2013].

Webb, Ruth (2009). Ekphrasis, Imagination and Persuasion in Ancient Rhetorical Theory and Practice. Farnham, Surrey: Ashgate. 